\title{
Diversity of Rainfall Thresholds for early warning of hydro-geological disasters
}

\author{
Davide L. De Luca and Pasquale Versace \\ Department of Informatics, Modelling, Electronics and System Engineering, University of Calabria, \\ Ponte P. Bucci, 41b building, 5th floor, Arcavacata di Rende (CS), 87036, Italy \\ Correspondence to: Davide L. De Luca (davide.deluca@unical.it)
}

Received: 1 December 2016 - Revised: 12 April 2017 - Accepted: 22 April 2017 - Published: 2 June 2017

\begin{abstract}
For early warning of disasters induced by precipitation (such as floods and landslides), different kinds of rainfall thresholds are adopted, which vary from each other, on the basis on adopted hypotheses. In some cases, they represent the occurrence probability of an event (landslide or flood), in other cases the exceedance probability of a critical value for an assigned indicator $I$ (a function of rainfall heights), and in further cases they only indicate the exceeding of a prefixed percentage a critical value for $I$, indicated as $I_{\mathrm{cr}}$. For each scheme, it is usual to define three different criticality levels (ordinary, moderate and severe), which are associated to warning levels, according to emergency plans. This work briefly discusses different schemes of rainfall thresholds, focusing attention on landslide prediction, with some applications to a real case study in Calabria region (southern Italy).
\end{abstract}

\section{Introduction}

Many example of Early Warning Systems (EWSs) of induced phenomena (such as landslides and floods) are described in literature. Relating to landslide forecasting, some examples are represented by the systems operating in Nagasaki (Yano and Senoo, 1985), California (Keefer et al., 1987), Rio de Janeiro (d'Orsi et al., 1997), New Zeeland (Glade et al., 2000), the UK (Cole and Davis, 2002), Hong Kong (Pun et al., 2003), Washington (Baum et al., 2005), Seattle (Baum and Godt, 2010), the Adriatic Danubian area in central and southern Europe (Guzzetti et al., 2007), Piedmont region in northern Italy (Capparelli and Tiranti, 2010). In this context, definition of rainfall thresholds represents an important component for an EWS; the literature is very huge for this topic and consequently many papers could be mentioned (as examples, Campbell, 1975; Caine, 1980; Innes, 1983; Cascini and Versace, 1986; Crosta, 1998; Reichenbach et al., 1998; Corominas, 2000; Crosta and Frattini, 2001; Aleotti, 2004; Wieczorek and Glade, 2005; Brunetti et al., 2010; Berti et al., 2012; Peres and Cancelliere, 2014; Segoni et al., 2014a, b; Vennari et al., 2014; Lagomarsino et al., 2015; Ciavolella et al., 2016). Rainfall thresholds can be easily calibrated on the basis of only information about historical movements, by using contingency tables and several skill scores (Giannechini et al., 2012; Martelloni et al., 2012; Gariano et al., 2015), and they can be straightforwardly used in real time as only knowledge about rainfall time series (predicted or observed in real time) is required to evaluate the exceedance of critical conditions.

Focusing the attention on Italy, in February 2016 the Department of Civil Protection published the operational guidance to unify alert messages related to EWSs of all the Italian Regions (http://www.protezionecivile.gov.it/jcms/it/ view_prov.wp?request_locale=it\&contentId=LEG56184). The document unifies the criticality and alert levels: both kinds of levels are now characterized by color codes (yellow, orange and red) and, for each of them, the associated event and risk scenarios are described. Nevertheless, no indication is provided concerning the identification of rainfall thresholds, to be used for estimating the criticality levels; consequently, each Regional Administration could have its own threshold scheme inside its EWS, and this obviously implies heterogeneity at national scale. In details, the increase of the criticality levels can be due to:

- the occurrence of events (heavy rainfalls, floods or landslides) with increasing characteristics in intensity, persistence along time and/or spatial extension. The refer- 
ence spatial scale is the alert zone (the Italian territory is subdivided in 137 alert zones) and the EWS generally includes rainfall forecasting based on meteorological models;

- an increase of probability associated to the event occurrence. The reference spatial scale is the municipal one, and the data recorded in real time by local monitoring networks are also considered.

Moreover, the concept of rainfall threshold is not associated with only one scheme; several approaches can be defined (Chacon et al., 2006; Guzzetti et al., 2008), with significant differences among them. This paper provides an overview of various schemes for rainfall thresholds, and a classification is proposed.

\section{Schemes for rainfall thresholds}

In general, it is possible to define an indicator $I$, which is a function of rainfall heights (observed and predicted) and can be correlated with the occurrence probability of an event $E$, which is indicated as $P[E]$ : this is a conditional probability and it is also written as $P[E \mid I]$. Examples of $I$ are: (1) discharge estimated with a Rainfall-Runoff model; (2) Safety Factor from a slope stability model; (3) the mean value of rainfall intensity on assigned durations, e.g. the classical Intensity-Duration (ID) schemes, adopted for landslide forecasting (Guzzetti et al., 2008). As a first aspect, the model adopted for defining the indicator can provide, for each forecasting interval, a single value of $I$ (Fig. 1a) or a probability distribution $F(I)$, connected to the imperfect knowledge of model parameters (Fig. 1b). The second distinction regards the probability $P[E \mid I]$, that can be generally expressed as (Fig. 1c):

$P[E \mid I]=\left\{\begin{array}{cc}0 & \text { if } I<I_{1} \\ g(I) & \text { if } I_{1} \leq I \leq I_{2} \\ 1 & \text { if } I>I_{2}\end{array}\right.$

where $g($.$) is a monotonic non decreasing function that as-$ sumes values between 0 and 1 into the interval $\left[I_{1} ; I_{2}\right]$; for $I<I_{1}$ the event is impossible, while it is certain when $I>I_{2}$. A simplification of Eq. (1) is represented by the step function (Eq. 2), obtained by assuming a critical value $I_{\mathrm{cr}}=I_{1}=I_{2}$ (Fig. 1d):

$P[E \mid I]= \begin{cases}0 & \text { if } I<I_{\mathrm{cr}} \\ 1 & \text { if } I \geq I_{\mathrm{cr}}\end{cases}$

The criterion for choosing $I_{\mathrm{cr}}$ greatly varies: for landslide prediction, as examples Godt et al. (2006) assume a lower limit above to which all the historical landslide events occurred, Cannon et al. (2008) set the threshold equal to an upper limit for which no False Alarm (see Sect. 3 for its definition) occurred. Moreover, $I_{\mathrm{cr}}$ can be chosen in order to minimize the sum of Missed and False Alarms (see Sect. 3 for their definition), by using specific optimization procedures (Bennet et al., 2013). A third and further distinction for the identification of rainfall thresholds regards the use of only the rainfall observed in real time (Fig. 1e), or also the predictions from meteorological and/or stochastic models (Fig. 1f), that usually provide an ensemble of realizations which can be or not equiprobable.

Overall, eight different schemes of rainfall thresholds can be adopted into an EWS: each one enables to derive values that set three different criticality levels (ordinary, moderate and severe), denoted in the following as $\mathrm{CL}_{1}, \mathrm{CL}_{2}$ and $\mathrm{CL}_{3}$. As examples, in this work authors analyze four schemes of threshold.

The simplest one, indicated as Scheme A, (Fig. 2a), considers a deterministic value of $I$, defines the probability $P[E \mid I]$ on the basis on Eq. (2) and uses only the rainfall heights observed in real time. In this case, only the comparison between $I$ and $I_{\mathrm{cr}}$ is allowed, and $\mathrm{CL}_{1}, \mathrm{CL}_{2}, \mathrm{CL}_{3}$ can be assumed as prefixed percentages (indicated as $\xi_{1}, \xi_{2}$ and $\left.\xi_{3}\right)$ of $I_{\mathrm{cr}}$. It should be observed that, on the basis of Eq. (2), the occurrence probability $P[E \mid I]$ associated to $\mathrm{CL}_{1}, \mathrm{CL}_{2}$, $\mathrm{CL}_{3}$ is zero, and consequently this scheme can be used when the increase of a critical level indicates that the event is very close to occur.

The Scheme B (Fig. 2b) uses Eq. (1) for $P[E \mid I]$ and, like Scheme A, considers a deterministic value for $I$ and only rainfall heights observed in real time. Specific values of $P[E \mid I]$, denoted as $P_{1}, P_{2}, P_{3}$ and associated to $\mathrm{CL}_{1}, \mathrm{CL}_{2}$, $\mathrm{CL}_{3}$, respectively, correspond to particular occurrence probabilities for a landslide.

Unlike the previous schemes of threshold, the Scheme C (Fig. 2c) takes into account the imperfect knowledge of parameters (which are assumed as random variables with assigned probability distributions, Biondi and De Luca, 2015) related to the adopted model for $I$, and then it provides a probability distribution $F(I)$ as output. The probability $P[E \mid I]$ is defined by Eq. (2), and, also in this case, only observed rainfall heights are used. This scheme provides as a result the exceedance probability for $I_{\mathrm{cr}}$, and therefore $\mathrm{CL}_{1}$, $\mathrm{CL}_{2}, \mathrm{CL}_{3}$ can be associated to prefixed values of $P\left[I>I_{\mathrm{cr}}\right]$, which corresponds, on the basis of Eq. (2), to the occurrence probability of a landslide $P[E]$.

Lastly, the Scheme D (Fig. 2d) constitutes a generalization of the previous Scheme C, because it uses (together with rainfall heights observed in real time) rainfall predictions derived from meteorological and/or stochastic models, consisting of an ensemble of realizations, which induces an ensemble of probability distributions for $I$. Consequently, $P[E]$ is computed by using the theorem of total probability:

$P[E]=\sum_{i=1}^{k} P\left[E \mid F_{i}(I)\right] \cdot \alpha_{i}\left(F_{i}(I)\right)$

where $k$ is the total number of rainfall realizations, $F_{i}(I)$ is the probability distribution associated to the $i$ th realiza- 


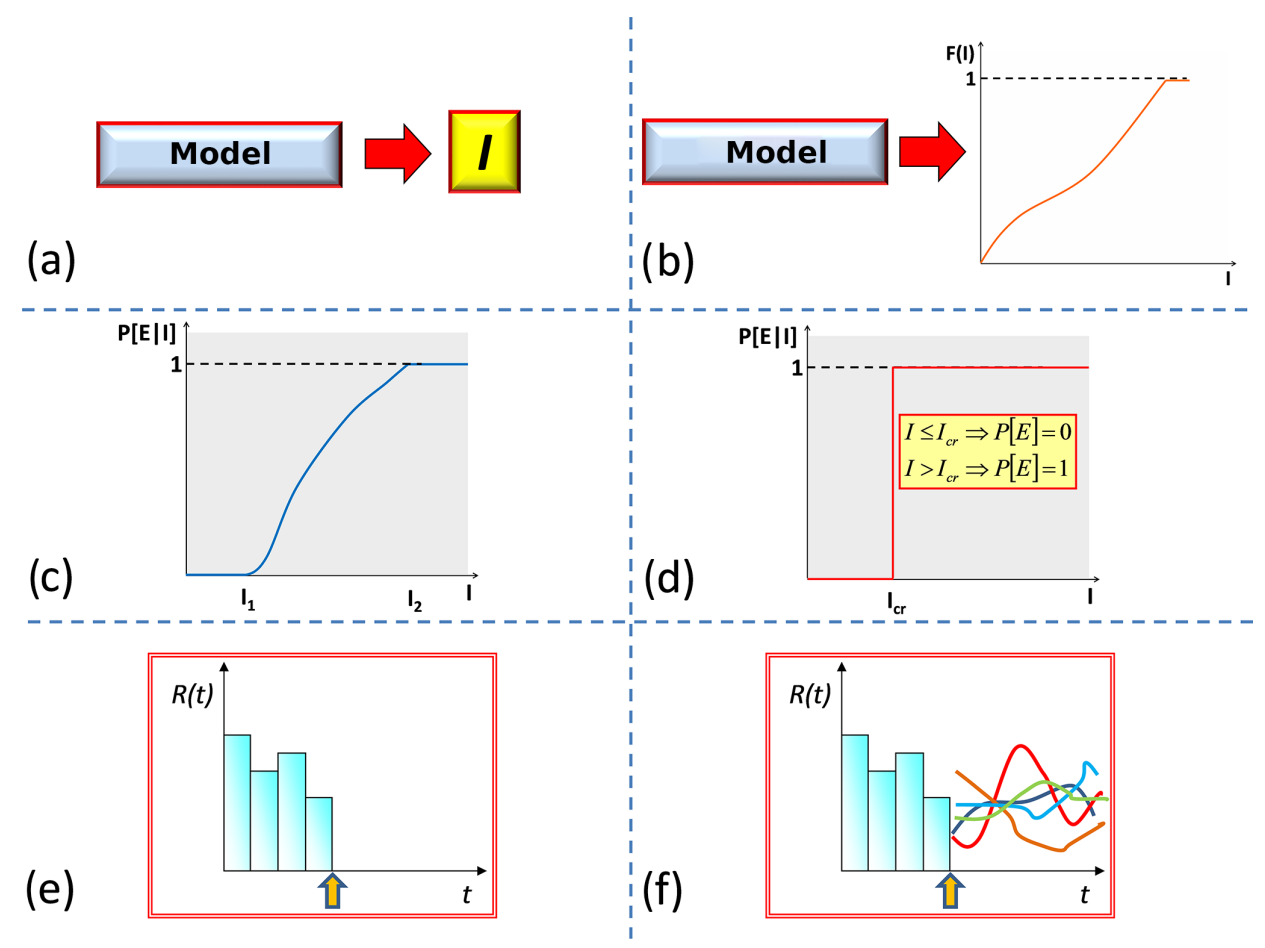

Figure 1. Several aspects characterizing a scheme for rainfall thresholds. Definition of $I$ : (a) deterministic value; (b) probability distribution $F(I)$. Modelling of $P[E \mid I]$ : (c) generic monotonic non-decreasing function; (d) step function. Use of rainfall input: (e) only data observed in real time; (f) also prediction from meteorological and/or stochastic models.

tion, $P\left[E \mid F_{i}(I)\right]$ is the landslide probability linked to the $i$ th realization, and $\alpha_{i}\left(F_{i}(I)\right)$ is the weight related to the $i$ th $F_{i}(I)$. The sum of all the weights is obviously equal to 1 , and each $\alpha_{i}\left(F_{i}(I)\right)$ corresponds to frequency of the associated $i$ th rainfall prediction in the ensemble of realizations. Similarly to Scheme C, the criticality levels correspond to prefixed values of $P[E]$.

\section{Application}

Concerning landslide prediction, an example of application of several rainfall threshold schemes is related to Gimigliano municipality, located in Calabria region (southern Italy, De Luca and Versace, 2017), characterized by an extension of about $32 \mathrm{~km}^{2}$. Bianchini et al. (2013) provided a good overview of geological settings in this area. 27 landslide events were selected (Table 1) from analysis of three databases: (1) the inventory of AVI project (italian acronym for Aree Vulnerate in Italia, that means Areas Affected by Landslides or Floods in Italy, Guzzetti et al., 1994); (2) ASICal Database (italian acronym for Aree Storicamente Inondate in Calabria, that means Historical Flooded areas in Calabria region, see http://www.camilab.unical.it/web/camilab/ prodotti-products); (3) DB0810 inventory, realized at CAMILab (visit www.camilab.unical.it for further details) for a Cooperation with Italian Department of Civil Protection, in which all landslide and flood events were collected for the period 2008-2010 in Calabria region. All the selected landslide events present a reduced uncertainty about occurrence date.

The most recent landslide events in Gimigliano caused several damages to buildings, road network, sewerage and water supply. As examples (Bianchini et al., 2013; De Luca and Versace, 2017):

- an earth slide occurred in January 2010 (code 22 in Table 1) on the slope of Corace river, which reactivated a dormant deep-seated landslide and the pre-existing displacement scarp surface enlarged. Bridge pylons on Corace river were seriously damaged, and consequently the provincial road across the bridge was closed, making impossible the road connections with the neighboring municipalities;

- a landslide occurred in February 2010 (code 23 in Table 1) on the metamorphic rock escarpment, threatening the buildings stability of the area named Gimigliano Superiore;

- in March 2010, a rainfall storm triggered a complex landslide (code 24 in Table 1) on the already unstable rock slope of Mt. Gimigliano: the mass movement evolved with soil erosion processes and from slides to flows, it was induced by springs formation in the land- 

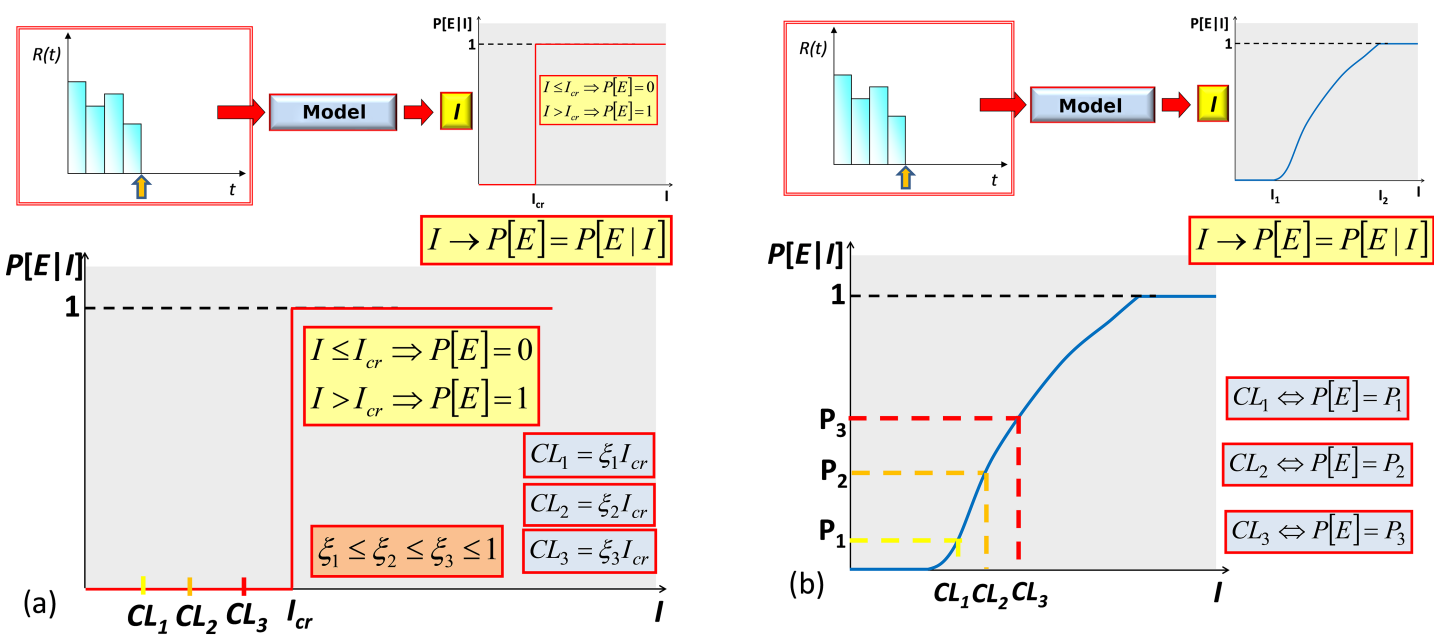

(b)
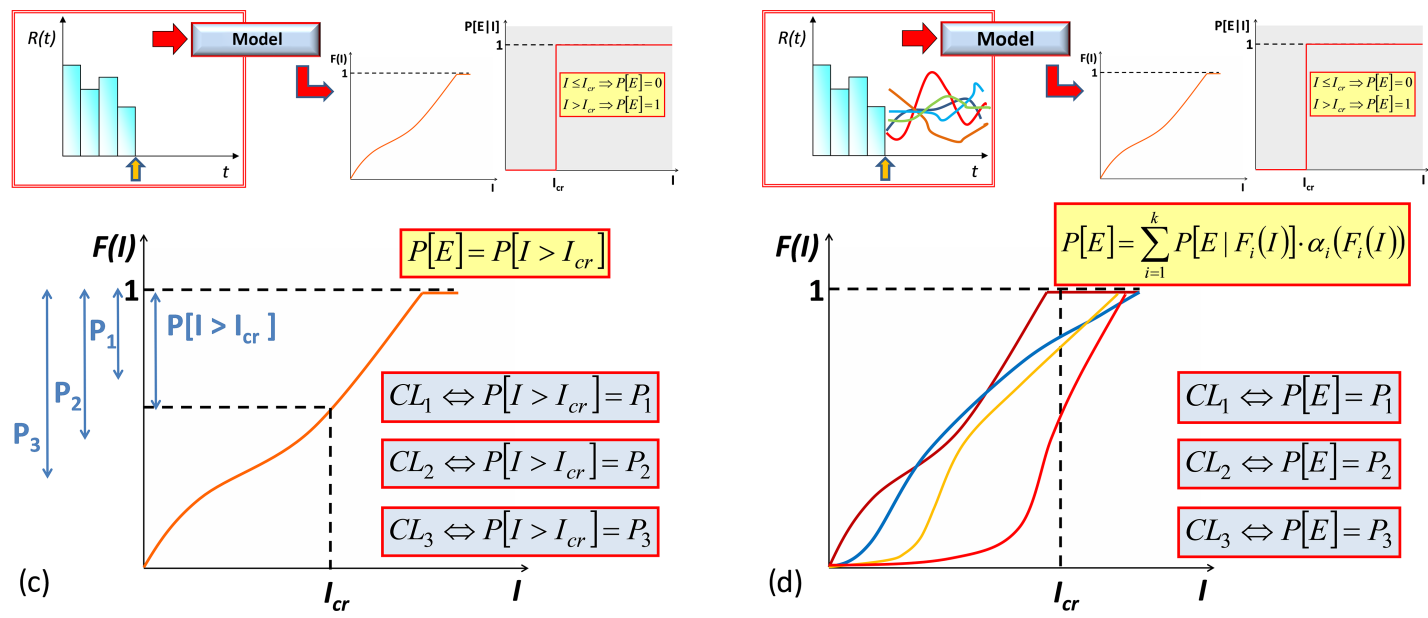

Figure 2. Examples of rainfall thresholds. (a) Scheme A: use of only rainfall data observed in real time, model providing a deterministic value for $I$, adoption of a step function for $P[E \mid I]$. (b) Scheme B: use of only rainfall data observed in real time, model providing a deterministic value for $I$, adoption of a generic monotonic non-decreasing function for $P[E \mid I]$. (c) Scheme C: use of only rainfall data observed in real time, model providing a probability distribution for $I$, adoption of a step function for $P[E \mid I]$. (d) Scheme D: use of rainfall predictions together with rainfall height observed in real time, model providing a probability distribution function for $I$, adoption of a step function for $P[E \mid I]$.

slide crown zone, and it produced saturation of pelitic terrains derived by weathered phyllite in some parts of the landslides body.

The rain gauge located at Tiriolo (see De Luca and Versace, 2017, for further details) was considered for rainfall analysis; authors used for application the daily time series, available from 1941, and the 20-min time series, available from 1992. All rainfall data were downloaded by the official website of the Multi Risk Center of Calabria region (www.cfd.calabria.it).

In details, FLaIR model (Forecasting of Landslides Induced by Rainfalls, Capparelli and Versace, 2011) was used as indicator, defined as a convolution between the rainfall Intensity $R($.$) and a filter function \psi($.$) , also named as transfer$ function:

$$
I(t)=\int_{t-M}^{t} R(\tau) \psi(t-\tau) \mathrm{d} \tau
$$

where $M$ represents the temporal memory of the process, and it depends on parameters of adopted filter $\psi$ (.). In Eq. (4) the dimensions are $[L / T]$ for $R(),.\left[T^{-1}\right]$ for $\psi($.$) , and [L / T]$ for $I($.$) . Authors used a mixture of exponential filter as \psi($. (De Luca and Versace, 2017), in order to better discriminate the influence of event and antecedent rainfall in the physical process of landslide trigger.

For this case study authors only considered rainfall heights observed in real time, and consequently results of FLaIR application regard Schemes A, B and C. For all schemes, a calibration period is related to the interval 1940-2006 (with 20 


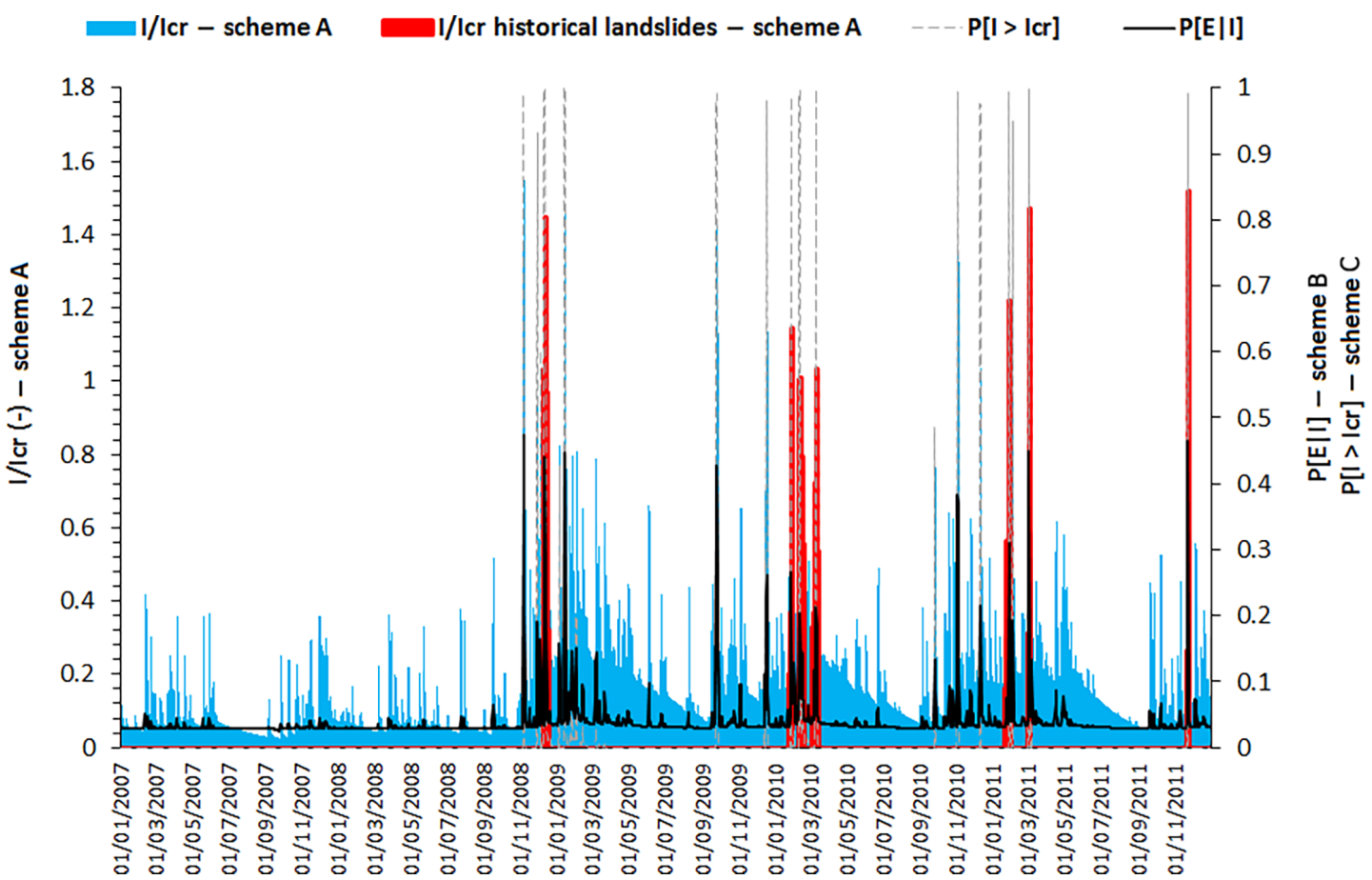

Figure 3. Application of FLaIR model - temporal behavior of $I / I_{\mathrm{cr}}$ (Scheme A), $P[E \mid I]$ (Scheme B) and $P\left[I>I_{\mathrm{cr}}\right]$ (Scheme C) in 20072011 for Gimigliano municipality (southern Italy).

Table 1. Gimigliano: list of the selected 27 landslide events.

\begin{tabular}{rrrr}
\hline Code & Date & Code & Date \\
\hline 1 & $11 / 03 / 1943$ & 15 & $25 / 12 / 1990$ \\
2 & $13 / 02 / 1954$ & 16 & $31 / 01 / 1996$ \\
3 & $13 / 11 / 1959$ & 17 & $03 / 10 / 1996$ \\
4 & $19 / 01 / 1972$ & 18 & $07 / 04 / 2003$ \\
5 & $02 / 01 / 1973$ & 19 & $28 / 11 / 2003$ \\
6 & $25 / 03 / 1973$ & 20 & $12 / 11 / 2004$ \\
7 & $07 / 11 / 1974$ & 21 & $13-16 / 12 / 2008$ \\
8 & $06 / 11 / 1976$ & 22 & $28 / 01 / 2010$ \\
9 & $21 / 10 / 1978$ & 23 & $10-13 / 02 / 2010$ \\
10 & $07 / 03 / 1980$ & 24 & $12 / 03 / 2010$ \\
11 & $16 / 12 / 1981$ & 25 & $28 / 01 / 2011$ \\
12 & $23 / 03 / 1982$ & 26 & $02 / 03 / 2011$ \\
13 & $16 / 11 / 1987$ & 27 & $23 / 11 / 2011$ \\
14 & $06 / 03 / 1988$ & & \\
\hline
\end{tabular}

landslide events), while 2007-2011 (with 7 landslide events) is the validation period. Starting from the contingency table (Fawcett, 2006; Barnes et al., 2009; Staley et al., 2013), which is composed by the number of:

- Correct Alarms (CA, also named True Positive, TP, i.e. historical landslides occurred when model output is above the threshold),

- Missed Alarms (MA, also named False Negatives, FN, i.e. landslides occurred but not predicted by the model),
- False Alarms (FA, also named False Positives, FP, i.e. landslides predicted by the model but not occurred),

- True Negatives (TN, i.e. model outputs are below the threshold and no landslide happened),

the metric Threat Score (TS, also named Critical Success Index, CSI, Gilbert, 1884; Schaefer, 1990):

$\mathrm{TS}=\frac{\mathrm{CA}}{\mathrm{CA}+\mathrm{MA}+\mathrm{FA}}$

was adopted as index for evaluating the performance of the considered threshold schemes. Similar results were obtained by using the index named as True Skill Statistic (TSS, Hanssen and Kuipersm, 1965; Peres and Cancelliere, 2014; Gariano et al., 2015).

Concerning calibration step (for further details, see Versace and De Luca, 2017):

- $I_{\mathrm{cr}}$ estimation provided a value equal to $17 \mathrm{~mm}$ day $^{-1}$ for Scheme A;

- starting from results of Scheme A, the probability $P[E \mid I]$ for Scheme B was evaluated in the following way: for different values of $I$ assumed as critical value, landslide probability is computed as ratio between CA and the number of model outputs above the threshold (i.e. $\mathrm{CA}+\mathrm{FA}$ ); 
Table 2. Gimigliano municipality (southern Italy): validation results (period 2007-2011) for Schemes A, B and C.

\begin{tabular}{|c|c|c|c|c|c|c|c|c|c|c|c|c|c|c|c|}
\hline \multicolumn{5}{|c|}{ Scheme A } & \multicolumn{6}{|c|}{ Scheme B } & \multicolumn{5}{|c|}{ Scheme C } \\
\hline$I_{\mathrm{cr}}\left(\mathrm{mm} \mathrm{day}^{-1}\right)$ & $\mathrm{CA}$ & MA & FA & $\mathrm{TS}$ & $P[E \mid I]$ & $\mathrm{CA}$ & MA & FA & TS & $I_{\mathrm{cr}}\left(\mathrm{mm} \mathrm{day}^{-1}\right)$ & $P\left[I>I_{\mathrm{cr}}\right]$ & $\mathrm{CA}$ & MA & FA & $\mathrm{TS}$ \\
\hline 17 & 7 & 0 & 6 & 0.54 & 0.10 & 7 & 0 & 14 & 0.33 & 12 & 0.50 & 7 & 0 & 9 & 0.44 \\
\hline & & & & & 0.15 & 7 & 0 & 11 & 0.39 & 14 & 0.60 & 7 & 0 & 8 & 0.47 \\
\hline & & & & & 0.20 & 7 & 0 & 6 & 0.54 & 17 & 0.70 & 7 & 0 & 8 & 0.47 \\
\hline & & & & & 0.25 & 5 & 2 & 5 & 0.42 & 19 & 0.80 & 7 & 0 & 8 & 0.47 \\
\hline & & & & & 0.30 & 4 & 3 & 4 & 0.36 & 21 & 0.90 & 7 & 0 & 7 & 0.50 \\
\hline & & & & & 0.35 & 3 & 4 & 4 & 0.27 & 22.5 & 0.95 & 7 & 0 & 6 & 0.54 \\
\hline & & & & & 0.40 & 3 & 4 & 3 & 0.30 & 24 & 0.99 & 6 & 1 & 5 & 0.50 \\
\hline
\end{tabular}

- as regards Scheme C, 2000 sets of filter parameters of FLaIR model were generated with a Monte Carlo approach and, for each set, $I_{\mathrm{cr}}$ was computed by adopting the same procedure used for Scheme A (Versace and De Luca 2017). For each day, $P\left[I>I_{\mathrm{cr}}\right]$ was set equal to the ratio between the number of simulations for which $I>I_{\mathrm{cr}}$ and the total number of simulations.

For validation period, the obtained results are shown in Fig. 3 and in Table 2. The temporal behavior of the dimensionless index $I / I_{\mathrm{cr}}$ is reported in Fig. 3 (histograms related to the left vertical axis), which also shows $P[E \mid I]$ (Scheme B) and $P\left[I>I_{\mathrm{cr}}\right]$ (Scheme C) along the time (lines related to the right vertical axis). For Scheme A, the estimated threshold $I_{\text {cr }}$ allows for reproducing all the historical events as CA, with $\mathrm{FA}=6$ and TS $=0.54$ : in fact, from Fig. 3 it is evident that all the landslide events (red histograms) present a dimensionless index greater than one. From a comparison between results for Schemes A and B (by analyzing Table 2), it should be noted that the threshold $I_{\mathrm{cr}}$ of Scheme A is not usually associated to high values of $P[E \mid I] ; I_{\mathrm{cr}}$ typically assumes low values in order to reproduce many landslide events as CA, but it can also imply an increase of FA (and, consequently, a decrease of the associated probability of landslide occurrence). Conversely, the use of scheme $\mathrm{B}$ requires attention on the choice of $P[E \mid I]$ associated to the critical level $\mathrm{CL}_{3}$, which is the most severe: an increase of probability clearly induces a reduction of FA, but it also implies an increase of MA, which could be significant. The maximization of a metric like TS could help the choice of the optimal values for $P_{1}, P_{2}$, and $P_{3}$ (Fig. 2b). More specifically, $I_{\mathrm{cr}}$ of Scheme A corresponds to a probability $P[E \mid I]$ of Scheme B equal to 0.2 (Table 2), and in validation period all the landslide events are associated to $P[E \mid I]$ values (represented by solid black lines in Fig. 3) which do not exceed 0.5. Concerning the differences among probability values in Schemes B and $\mathrm{C}$ (represented in Fig. 3 by solid black and dashed grey lines, respectively), the diverse meaning of probability in these approaches should be considered: (1) Scheme B uses a nonstep function (Eq. 1); (2) Scheme C adopts a step function (Eq. 2) and takes into account the imperfect knowledge of filter parameters. Therefore, in the former, $P$ is the probability of landslide occurrence depending on the current value of
I (by considering the unique parameters set of FLaIR model which is estimated in Scheme A), while in the latter it is the probability for which $I>I_{\mathrm{cr}}$ (estimated with the procedure indicated in the third point of the previous bulleted list, i.e. by generating 2000 sets of filter parameters of FLaIR model and then estimating the specific $I_{\mathrm{cr}}$ for each set). Consequently, it is expected that Scheme $\mathrm{C}$ provides high values of probability in correspondence of landslide events: for the selected case study $P\left[I>I_{\mathrm{cr}}\right]$ is greater than 0.9 (see dashed grey lines in Fig. 3). For both Schemes B and C, the optimal values for the threshold probabilities $P_{1}, P_{2}$, and $P_{3}$ (Fig. $2 \mathrm{~b}$ and c) can be carried out by analysis of the metric TS (Table 2 ).

\section{Conclusions}

A scheme of rainfall threshold has to be carefully defined, in order to avoid confusion in its use in EWSs. The main distinction regards deterministic and probabilistic schemes. For landslide prediction, examples of deterministic approaches (like Scheme A in this paper) are the classical IntensityDuration (ID) models (Guzzetti et al., 2008) or FLaIR model (Capparelli and Versace, 2011). Instead, probabilistic thresholds consider a generic monotonic and non-decreasing function for modelling the occurrence probability of a landslide (Scheme B), or take into account the imperfect knowledge of parameters of the adopted model for the indicator $I$ (like Schemes $\mathrm{C}$ and $\mathrm{D}$ ), or use an ensemble of rainfall predictions from meteorological and/or stochastic models (Scheme D). In any case, the use of suitable metrics like Threat Score (TS) allows for evaluating performance in terms of Correct, Missed and False alarms, and consequently for choosing the optimal values for the criticality levels $\mathrm{CL}_{1}, \mathrm{CL}_{2}$ and $\mathrm{CL}_{3}$.

For the selected case study, threshold value $I_{\mathrm{cr}}$ of Scheme A corresponds to a low probability of landslide occurrence (0.2). The probability distribution, derived from Scheme B, provides much more information, because it allows to associate different values of $I(t)$, assumed as $I_{\mathrm{cr}}$, to occurrence probability of a landslide. Finally, from Scheme C it is possible to evaluate the probability associated to the exceedance $I(t)>I_{\mathrm{cr}}$, by considering filter parameters as random variables: $P\left[I>I_{\mathrm{cr}}\right]$ is very different from that obtained 
in Scheme B, and then attention is necessary in making decisions on the basis of probability values.

Data availability. All the used data are available at www.cfd. calabria.it after registration.

Competing interests. The authors declare that they have no conflict of interest.

Edited by: R. Greco

Reviewed by: three anonymous referees

\section{References}

Aleotti, P. A warning system for rainfall-induced shallow failures, Eng. Geol., 73, 247-265, https://doi.org/10.1016/j.enggeo.2004.01.007, 2004.

Barnes, L. R., Schultz, D. M., Gruntfest, E. C., Hayden, M. H., and Benight, C. C.: Corrigendum: False alarm rate or false alarm ratio?, Weather Forecast., 24, 1452-1454, https://doi.org/10.1175/2009WAF2222300.1, 2009.

Baum, R. L. and Godt, J. W.: Early warning of rainfall-induced shallow landslides and debris flows in the USA, Landslides, 7, 259272, https://doi.org/10.1007/s10346-009-0177-0, 2010.

Baum, R. L., Godt, J. W., Harp, E. L., McKenna, J. P., and McMullen, S. R. Early warning of landslides for rail traffic between Seattle and Everett, Washington, USA, Proceedings of Conference on Landslide Risk Management (Vancouver), 731740, 2005

Bennett, N. D., Croke, B. F. W., Guariso, G., Guillame, J. H. A., Hamilton, S. H., Jakeman, A. J., Marsili-Libelli, S., Newham L. T. H., Norton, J. P., Perrin, C., Pierce, S. A., Robson, B., Seppelt, R., Voinov, A. A., Fath, B. D., and Andreassian, V.: Characterising performance of environmental models, Environ. Model. Softw., 40, 1-20, https://doi.org/10.1016/j.envsoft.2012.09.011, 2013.

Berti, M., Martina, M. L. V., Franceschini, S., Pignone, S., Simoni, A., and Pizziolo, M.: Probabilistic rainfall thresholds for landslide occurrence using a Bayesian approach, J. Geophys. Res.-Earth, 117, F04006, https://doi.org/10.1029/2012JF002367, 2012.

Bianchini, S., Cigna, F., Del Ventisette, C., Moretti, S., and Casagli, N.: Monitoring Landslide-Induced Displacements with TerraSAR-X Persistent Scatterer Interferometry (PSI): Gimigliano Case Study in Calabria Region (Italy), Int. J. Geosci., 4, 1467-1482, 2013.

Biondi, D. and De Luca, D. L.: Process-based design flood estimation in ungauged basins by conditioning model parameters on regional hydrological signatures, Nat. Hazards, 79, 1015-1038, https://doi.org/10.1007/s11069-015-1889-1, 2015.

Brunetti, M. T., Peruccacci, S., Rossi, M., Luciani, S., Valigi, D., and Guzzetti, F.: Rainfall thresholds for the possible occurrence of landslides in Italy, Nat. Hazards Earth Syst. Sci., 10, 447-458, https://doi.org/10.5194/nhess-10-447-2010, 2010.

Caine, N.: The rainfall intensity-duration control of shallow landslides and debris flows, Geogr. Ann. A, 62, 23-27, 1980.
Campbell, R. H.: Soil slips, debris flows, and rainstorms in the Santa Monica Mountains and vicinity, southern Californiam in: US Geological Survey Professional Paper 851, Washington DC, U.S. Government Printing Office, 51 pp., 1975.

Cannon, S. H., Gartner, J. E., Wilson, R., Bowers, J., and Laber, J.: Storm rainfall conditions for floods and debris flows from recently burned areas in southwestern Colorado and southern California, Geomorphology, 96, 250-269, https://doi.org/10.1016/j.geomorph.2007.03.019, 2008.

Capparelli, G. and Tiranti, D.: Application of the MoniFLaIR early warning system for rainfall-induced landslides in Piedmont region (Italy), Landslides, 7, 401-410, https://doi.org/10.1007/s10346-009-0189-9, 2010.

Capparelli, G. and Versace, P.: FLaIR and SUSHI: Two mathematical models for Early Warning Systems for rainfall induced landslides, Landslides, 8, 67-79, https://doi.org/10.1007/s10346010-0228-6, 2011.

Cascini, L. and Versace, P.: Eventi pluviometrici e movimenti franosi, Proceedings of XVI Italian Conference on Geotechnics, Bologna 14-16 May 1986, Volume II, 171-184, 1986 (in Italian).

Chacon, J., Irigaray C., Fernandez, T., and Hamdouni, R. El.: Engineering geology maps: landslides and geographical information systems, B. Eng. Geol. Environ., 65, 341-411, https://doi.org/10.1007/s10064-006-0064-z, 2006.

Ciavolella, M., Bogaard, T., Gargano, R., and Greco, R.: Is there predictive power in hydrological catchment information for regional landslide hazard assessment?, Procedia Earth and Planetary Science, 16, 195-203, https://doi.org/10.1016/j.proeps.2016.10.021, 2016.

Cole, K. and Davis, G. M.: Landslide warning and emergency planning systems in West Dorset, England, in: Instability, Planning and Management, edited by: McInnes, R. G. and Jakeways, J., Thomas Telford, London, UK, 463-470, 2002.

Corominas, J.: Landslides and climate, Keynote lecture, in: Proceedings 8th International Symposium on Landslides, edited by: Bromhead, E., Dixon, N., and Ibsen, M. L., Cardiff, A.A. Balkema, 4, 1-33, 2000.

Crosta, G.: Regionalization of rainfall thresholds: An aid to landslide hazard evaluation, Environ. Geol., 35, 131-145, https://doi.org/10.1007/s002540050300, 1998.

Crosta, G. B. and Frattini, P.: Rainfall thresholds for triggering soil slips and debris flow, in: Proceedings 2nd EGS Plinius Conference on Mediterranean Storms, edited by: Mugnai, A., Guzzetti, F., and Roth, G., Siena (Italy), 463-487, 2001.

De Luca, D. L. and Versace, P.: A comprehensive framework for empirical modeling of landslides induced by rainfall: the Generalized FLaIR Model (GFM), Landslides, 14, 1009-1030, https://doi.org/10.1007/s10346-016-0768-5, 2017.

D’Orsi, R., D’Avila, C., Ortigao, J. A. R., Dias, A., Moraes, L., and Santos, M. D.: Rio-Watch: the Rio de Janeiro landslide watch system, in: Proceedings of the 2nd PSL Pan-AM Symposium on Landslides, Rio de Janerio 1, 21-30, 1997.

Fawcett, T.: An introduction to ROC analysis, Pattern Recognition Letters, 27, 861-874, https://doi.org/10.1016/j.patrec.2005.10.010, 2006.

Gariano, S. L., Brunetti, M. T., Iovine, G., Melillo, M., Peruccacci, S., Terranova, O., Vennari, C., and Guzzetti, F.: Calibration and validation of rainfall thresholds for shallow landslide fore- 
casting in Sicily, southern Italy, Geomorphology, 228, 653-665, https://doi.org/10.1016/j.geomorph.2014.10.019, 2015.

Giannecchini, R., Galanti, Y., and D'Amato Avanzi, G.: Critical rainfall thresholds for triggering shallow landslides in the Serchio River Valley (Tuscany, Italy), Nat. Hazards Earth Syst. Sci., 12, 829-842, https://doi.org/10.5194/nhess-12-829-2012, 2012.

Gilbert, G. K.: Finley's tornado predictions, Amer. Meteor. J., 1, 166-172, 1884.

Glade, T., Crozier, M. J., and Smith, P.: Applying probability determination to refine landslide-triggering rainfall thresholds using an empirical "Antecedent Daily Rainfall Model”, Pure Appl. Geophys., 157, 1059-1079, 2000.

Godt, J. W., Baum, R. L., and Chleborad, A. F.: Rainfall characteristics for shallow landsliding in Seattle, Washington, USA, Earth Surf. Proc. Landf., 31, 97-110, https://doi.org/10.1002/esp.1237, 2006.

Guzzetti, F., Cardinali, M., and Reichenbach, P.: The AVI Project: A bibliographical and archive inventory of landslides and floods in Italy, Environ. Manage., 18, 623-633, https://doi.org/10.1007/BF02400865, 1994.

Guzzetti, F., Peruccacci, S., Rossi, M., and Stark, C. P.: Rainfall thresholds for the initiation of landslides in central and southern Europe, Meteorol. Atmos. Phys., 98, 239-267, https://doi.org/10.1007/s00703-007-0262-7, 2007.

Guzzetti, F., Peruccacci, S., Rossi, M. and Stark, C. P.: The rainfall intensity-duration control of shallow landslides and debris flows: An update, Landslides, 5, 3-17, https://doi.org/10.1007/s10346007-0112-1, 2008.

Hanssen, A. W. and Kuipers, W. J. A.: On the relationship between the frequency of rain and various meteorological parameters, Staatsdrukkerij- en Uitgeverijbedrijf, 1965.

Innes, J. L.: Debris flows, Prog. Phys. Geog., 7, 469-501, https://doi.org/10.1177/030913338300700401, 1983.

Keefer, D. K., Wilson, R. C., Mark, R. K., Brabb, E. E., Brown III, W. M., Ellen, S. D., Harp, E. L., Wieczoreck, G. F., Alger, C. S., and Zatkin, R. S.: Real-time landslide warning during heavy rainfall, Science, 238, 921-926, 1987.

Lagomarsino, D., Segoni, S., Rosi, A., Rossi, G., Battistini, A., Catani, F., and Casagli, N.: Quantitative comparison between two different methodologies to define rainfall thresholds for landslide forecasting, Nat. Hazards Earth Syst. Sci., 15, 2413-2423, https://doi.org/10.5194/nhess-15-2413-2015, 2015.

Martelloni, G., Segoni, S., Fanti, R., Catani, F.: Rainfall thresholds for the forecasting of landslide occurrence at regional scale, Landslides, 9, 485-495, https://doi.org/10.1007/s10346011-0308-2, 2012.

Peres, D. J. and Cancelliere, A.: Derivation and evaluation of landslide-triggering thresholds by a Monte Carlo approach, Hydrol. Earth Syst. Sci., 18, 4913-4931, https://doi.org/10.5194/hess-18-4913-2014, 2014.
Pun, W. K., Wong, A. C. W., and Pang, P. L. R.: A review of the relationship between rainfall and landslides in Hong Kong, Proceedings of 14th Southeast Asian Geotechnical Conference, 3, 211-216, 2003.

Reichenbach, P., Cardinali, M., De Vita, P., and Guzzetti, F.: Regional hydrological thresholds for landslides and floods in the Tiber River Basin (central Italy), Environ. Geol., 35, 146-159, https://doi.org/10.1007/s002540050301, 1998.

Schaefer, J. T.: The Critical Success Index as an indicator of warning skill, Weather Forecast., 5, 570-575, https://doi.org/10.1175/1520 0434(1990)005<0570:TCSIAA>2.0.CO;2, 1990.

Segoni, S., Rossi, G., Rosi, A., and Catani, F.: Landslides triggered by rainfall: a semiautomated procedure to define consistent intensity-duration thresholds, Comput. Geosci., 63, 123131, https://doi.org/10.1016/j.cageo.2013.10.009, 2014a.

Segoni, S., Rosi, A., Rossi, G., Catani, F., and Casagli, N.: Analysing the relationship between rainfalls and landslides to define a mosaic of triggering thresholds for regional-scale warning systems, Nat. Hazards Earth Syst. Sci., 14, 2637-2648, https://doi.org/10.5194/nhess-14-2637-2014, 2014 b.

Staley, D. M., Kean, J. W., Cannon, S. H., Schmidt, K. M., and Laber, J. L.: Objective definition of rainfall intensity-duration thresholds for the initiation of post-fire debris flows in southern California, Landslides, 10, 547-562 https://doi.org/10.1007/s10346-012-0341-9, 2013.

Vennari, C., Gariano, S. L., Antronico, L., Brunetti, M. T., Iovine, G., Peruccacci, S., Terranova, O., and Guzzetti, F.: Rainfall thresholds for shallow landslide occurrence in Calabria, southern Italy, Nat. Hazards Earth Syst. Sci., 14, 317-330, https://doi.org/10.5194/nhess-14-317-2014, 2014.

Versace, P. and De Luca, D. L.: Deterministic and probabilistic rainfall thresholds for landslide forecasting, Proceedings of World Landslide Forum 4, Ljubljana, Slovenia, Springer International Publishing AG 2017, Advancing Culture of Living with Landslides, https://doi.org/10.1007/978-3-319-53485-5_18, 2017.

Wieczorek, G. F. and Glade, T.: Climatic factors influencing occurrence of debris flows, in: Debris flow Hazards and Related Phenomena, edited by: Jakob, M., Hungr, O., Springer Berlin Heidelberg, 325-362, 2005

Yano, K. and Senoo, K.: How to set standard rainfalls or debris flow warning and evacuation, Sabo Symposium (SEDD Japan), 451457, 1985. 